\title{
Approaching Development Projects from a Human Development and Capability Perspective
}

\section{Alexandre Apsan Frediani, Alejandra Boni and Des Gasper}

Abstract: The paper discusses the relevance of the human development and capability approach for development project planning, management and evaluation. With reference to the set of five other studies that it introduces, it suggests in which areas insights from human development-and-capability thinking offer advances and in which areas such thinking needs to link with and be complemented or corrected by thinking from other sources and traditions. The paper aims at capturing the learning from recent experiences and studies, both for project planning and for the human capabilities perspective.

Keywords: project planning; project evaluation; capability approach; participatory planning; human agency; human rights

\section{Introduction}

The human development and capability approach (in brief: 'capability approach'1) aspires to re-orient approaches to socio-economic development and public policy, away from taking economic growth and/or declared subjective well-being as the overriding objectives, and towards improving the ability of persons to lead a life that they have reason to value. It has much to contribute in critique of the traditional and still common focus in project planning only on production of things and not on their influence on the lives of people. How though can one practically apply the approach to development projects?

Project planning (including design), management and evaluation present a central and complex domain within which to operationalize the capability approach, where actors involved in human development work require constructive suggestions. Yet the capability approach has not, to date, said very much about development projects (For partial exceptions, see: Oosterlaken and vdHoeven, 2012 with an emphasis on design; Frediani, 2007, Schischka et al., 2008 and Biggeri, Ballet and Comim, 2011 with an emphasis on monitoring and evaluation; and Alkire, 2002, Frediani, 2010, and Kleine, 2013 with an emphasis on the framing of development projects). Whereas there is an established human rights based approach to planning (see, for example, the United Nations' HRBA Portal), there is no equally established human development based partner and complement. This special issue highlights and addresses that gap. It asks what the capability approach could offer to project planning and management, and what it needs to recognise and add to itself in order to do so. The set consists of this overview paper and five others.

The second paper, by Alvaro Fernandez-Baldor, Alejandra Boni, Pau Lillo and Andres Hueso, illustrates the dimensions of important effects that can be neglected in conventional approaches to project planning and evaluation and unearthed by a human capability perspective. Fernandez-Baldor et al. especially discuss impacts on a variety of 'opportunity freedoms' beyond the intended project objectives. The later paper by Muniz Castillo likewise discusses two vital such types of often neglected effect, the impacts on

\footnotetext{
${ }^{1}$ While using the term 'capability approach', this editorial piece hopes to highlight the importance of complementing it with notions emerging from the literature on 'human development' that contributes to its operationalization in the field of project planning.
} 
participants' motivation and on their real capacities.

The third paper, by Gabriel Ferrero and Carlos Zepeda, offers a diagnosis of weaknesses in mainstream project approaches, which are approaches that largely derive originally from engineering. It proposes an alternative, centred on 'process freedoms', that focuses not on pre-defining a target outcome of fulfilment of some supposedly agreed objectives within a given time and via a complete plan for how to achieve it, but on support to processes of local empowerment, involving learning, visioning, choice and cooperation. Ferrero and Zepeda offer a broad critique and an alternative vision, rather than detailed methods.

The subsequent three papers offer more specific treatments of selected aspects that correspond to some elements of the agenda of issues generated by the first three, concerning both 'opportunity freedoms' and 'process freedoms'.

The fourth paper, by Julian Walker, uses the human capability perspective to enrich an existing tool, the time use survey, a standard instrument in research on wellbeing and gender equity. In contrast, the fifth, by Mario Biggeri and Andrea Ferrannini, uses existing tools in participatory research to strengthen the human capability perspective, and to build a method, 'Opportunity Gap analysis', that can effectively structure focus group discussions. It includes also a basic extension of the capability approach - a focus on change over time - to make it more relevant in project planning.

The last paper, by Mirtha Muniz Castillo, shows how aspects neglected in mainstream planning and management - the impact of project practices on autonomous capacity of project participants - are critical for the sustainability of projects, and offers ideas for how to adequately reflect this in design and evaluation. The paper addresses issues of longer term change, organizational culture and politics that are also introduced by Ferrero and Zepeda and later in this overview paper. Like the other papers it illustrates the importance of pursuing a human capability agenda in project planning by drawing on sources other than only Sen, Nussbaum or literatures that cite them or are cited by them.

\section{Planning and managing development projects}

'Development projects' are a contested set of practices in struggles for human development, justice and equity. The project-oriented approach to development has aimed to enhance efficiency in use of resources and to facilitate coordinated action. Development agencies have increasingly adopted project management tools drawn from business management and 'new public management', that lay out precise and detailed blueprints for time-bound action, to assure, supposedly, that initiatives are transparent, achievable and accountable.

Critics have pointed out characteristic limitations of such thinking. Part of the set of critiques is technical in nature, part is political. First, as just mentioned, a focus on the intended creation and timely delivery of things leads to lack of attention to projects' full range of effects, not only intended effects, on people: including individual people not only 'households'. For example, the electrification projects studied by Fernandez-Baldor et al. expanded capabilities in some areas not planned for or evaluated by the project engineers but highly valued by those affected: they improved night-time security, promoted connections with other people, and encouraged study in the evenings.

Second, as noted by Ferrero and Zepeda, the lack of focus on people as complex actors is associated with a neglect of the values and principles that inspire action and with neglect of promotion of agency. This lack of attention undermines projects' longer term sustainability.

Third, the blueprint orientation underestimates more generally the complexity of 
situations and the ubiquity of potential disruptions. Such a methodology assumes "social change and innovation to be both predictable in advance and achievable by linear and logical planning methods" (Mowles et al., 2008: 809). But, as stressed in human security analyses, real contexts are much more unpredictable-well illustrated in the papers by Fernandez-Baldor et al., Ferrero and Zepeda, and Muniz Castillo_-and require more flexible responses.

Fourth, related to the insufficient thinking about values, 'project planning' has considered itself to be a planning methodology based only on a rational, pragmatic and neutral perspective, but that stance in fact typically perpetuates existing social imbalances (Moser, 1993). According to Moser, such a project-planning approach often focuses on manifestations of deprivation (e.g., access to food, water, sanitation and shelter), failing to address the underlying set of social relations. Similarly, Moncrieffe (2007) argues that the 'target population' discourse of development projects has objectified recipients and generated labels that homogenize groups under essentialist categories. As a consequence, development projects have characteristically focused on distribution of goods and services to such essentialistically-defined groups (e.g., women, children, people with disabilities), leaving unchallenged the relations that generate injustices, and leaving unconsidered the implications of the intersection of the numerous relevant attributes that define a person and her situation. Managerialism applied in development planning contributes towards an ahistorical and apolitical approach to addressing injustices that reduces development agencies' capacity to bring about substantial needed change (Lewis, 2008). Within such an approach, even participatory projects and planning can become 'participulation', tools of control by the existing powers, as Ferrero and Zepeda observe.

This special issue asks: What is the added value of approaching development projects from a capability perspective? How far does or can the capability approach contribute to addressing concerns raised by these critical perspectives on development projects? And how does it relate to the range of alternative project planning approaches that already exist?

A well known earlier response by Alkire (2002) argued that managing development projects from a capability perspective means: 1) understanding participants as 'agents of change', rather than merely beneficiaries; 2) focusing on obtaining outcomes that people value, not purely predefined aims set by development agencies and donors; and 3) following principles of enhancing empowerment and self-determination, to support project sustainability and responsiveness. These principles highlight that 'who decides' and 'how it is decided' are equally important as 'what is decided'. The present set of papers tries to go further with these issues.

\section{The capability approach -1 : the capability criterion}

The capability approach began as a reaction against mainstream positions in welfare economics and in political philosophy and ethics, that gave priority as evaluative criterion to one or more of: resource holdings; income; preference fulfilment; measured or imputed felt satisfaction. It presented an alternative priority criterion, capability: the access to functionings that we have (good) reason to value ('opportunity freedom'). As it grew into a conception of human development, it elaborated its picture of functioning as a human person, to emphasise the importance of 'process freedom', the ability to participate in the decision-making that influences this structure of opportunities. The 2010 Human Development Report included not only capability expansion but process freedoms, and other principles including basic needs, sustainability and human rights, in the core conception of human development. Going further, authors like Nussbaum and Pick have explored the processes of growth of abilities to reflect, participate, decide and 
act (e.g., Nussbaum 2001, 2011; Pick and Sirkin 2010), thus connecting to an earlier and more widely known usage of 'human development', from developmental psychology and education. People are 'time-travellers', living in time and evolving; we touch later on some of the implications.

So the capability approach looks at how people can live their lives, not only what things they possess or how much income they receive. The paper by Walker considers time poverty. He notes that being short of time is not per se an indicator of poverty. From a human development perspective we must ask about the life alternatives that people have, and their ability to achieve what they have good reason to value. Can, for example, a person avoid income poverty only by working such long hours that the rest of their life is marred by time pressure? Conversely, a project that increases people's 'free time' is not automatically a development advance. Does, for example, a shift to sale of their produce from their homes save their time but also curtail their opportunities for visiting market centres, mixing with other people, and controlling the income from their produce? What are the socially permitted uses for their 'saved' time?

The capability criterion emphasises access to valuable functionings without insistence on achievement of the functionings themselves. The rationale of adopting this criterion, rather than a lead criterion of respecting well-informed well-reasoned choice, is not because of 'adaptive preferences'; in fact nearly all preferences are socially influenced and evolve. Its rationale includes, but is not only, a respect for free choice, by individuals or groups. While centred in respect for individuals, the principle of choosing in terms of capability arises specifically for public (or inter-personal) decision-making. Individuals do not choose for themselves (at least for themselves today) in terms of a capability criterion rather than a preference criterion; but when individuals or groups are choosing for other individuals (e.g. their children) or the political community of which they are a member, or regarding how to support another community, they may adopt this criterion, viz.: which reasoningly valued opportunities are really open and fulfillable for a person in the given situation. Biggeri and Ferrannini underline thus that the capability criterion concerns public prioritization, community choices, not individuals' choices for themselves: 'community capabilities represent all the valuable functionings and opportunities that "should" be guaranteed for all members of the community living in a given place, thus constituting the central focus of the analysis and the road map for identifying areas for policy programming and implementation'. In other words, capability expansion is a criterion in (liberal) public policy (Gasper, 2009). Correspondingly, the realm of public policy is where individual deliberations do not suffice, due to the classic challenges of externalities, merit goods, information gaps and distortions, and more.

\section{The capability approach - 2: Attention to diversity and intersectionality}

One pillar of the capability approach is attention to diversity of persons and diversity in their circumstances. The basic heterogeneity of human beings is crucial in the assessment of (in)equality (Sen, 1992) and for understanding human functionings. People differ along (a) a personal axis (e.g., gender, age, class, etc); (b) an intersecting external or environmental axis (wealth, climate, etc.) and (c) along an inter-individual or social axis (Walker, 2006).

Diversity and intersectionality have strong implications for the analysis of development interventions. They can: 1) explain differences in people's abilities to convert resources into capabilities and functionings, and differences in their agency; 2) allow us to scrutinize the adaptive preferences of persons and deprived groups; and 3) help us to understand identities and to question labelling. 
The first of these implications is central to the paper by Fernández-Baldor et al. It highlights how the impacts of technological inputs, such as the energy brought through four electrification projects in Peruvian rural communities, differ between men and women. Most of the projects did not strengthen women's agency. Technology users differ in terms of several intersecting dimensions. These include personal differences and social differences; for instance race, ethnic, or gender differences can be salient with regard to technology. So human diversity is stressed in the approach by an explicit focus on personal and socio-environmental factors that affect the conversion of resources into functionings, and on the social, institutional, and environmental context that affect the conversion factors and the capability set directly. This analysis has major implications for project planning, including that additional types of information should be collected (on values, customs, gender roles, leadership in the community, etc.) and that the active role of women should be boosted in the implementation and management of the technology.

Another key idea that the capability approach can bring into project planning concerns each person's multiple identities and, consequently, the dangers of labelling. 'Everyone has many identities. Being a man or a woman is one of them. Being a member of a family is another. Membership of a class, an occupation group, a nation or a community can be the basis of particular links. One's individuality coexists with a variety of such identities. Our understanding of our interests, well-being, obligations, objectives, and legitimate behavior is influenced by the various - and sometimes conflicting - effects of these diverse identities.' (Sen, 1990:125). However, in mainstream project planning there is a tendency to homogenize big categories of intended beneficiaries under an assigned label (women, older, disabled, children, etc.), forgetting the multiple identities that people have and bringing perverse effects in many cases. As argued by Moncrieffe and Eyben (2007), even when there is altruistic intent, labelling can misrepresent people, stigmatize whole categories, and even incite or sustain social and political discord.

Although labelling has not been a central topic in the capability literature, it is considered by Trani et al. (2011) in their analysis of public policies with regard to disability and by Walker et al. (2013) in their study of urban projects in Mumbai, India. Both studies argue that the capability approach allows us to consider the multiple differences between people. As Trani et al. emphasize, "it avoids labelling by classiffing persons with disabilities based on their impairment only which leads to a uniform and inadequate provision of services" (Trani et al., 2011: 144).

Walker et al. (2013) suggest a strategic approach for organizations that want to avoid labelling and the imposition of social identities by outsiders and to promote rights and well-being of all of their constituents, including those with multiple subordinated identities. The organizations should recognize the intersectional nature of social identities and develop agendas for change that build platforms for social justice that unite, rather than fragment, identity-based claims. The capability approach can provide a framework to carry on that kind of research.

Intersectionality analysis helps also in identifying threats to specific sorts of person in specific social circumstances. Attempts to design relevant projects for climate change adaptation, for example, require this type of human security analysis. But: 'it is rare to see an academic or policy discourse about adaptation which identifies the specific risks that adaptation seeks to avoid, and to whom those risks most apply (such as, for example, the risk of increased malnutrition among women in the highlands of Papua New Guinea)' (Barnett 2011: 270). In the absence of a focus on specific types of people, analysis proceeds in terms of the 'needs' of 'the economy' or of physical structures, and downgrades the needs of poorer people, who are by far those most at risk (Gasper 2013).

Specific threats combine, to produce overall vulnerability. Old people, for example, who are already particularly vulnerable in the face of climate change (O'Brien 
and Leichenko 2007), are exposed also to changes in family structure that leave more of them living alone and to public policy regimes that leave them without compensating support. Human security analysis looks at these vital combinations and specific intersections in persons' lives. 'An emphasis on human capabilities and human security draws attention to the differential consequences of climate change for individuals and communities resulting first and foremost from disparities in human development' (O'Brien and Leichenko, 2007, p. 14), and establishes the basis for relevant adaptation project design. It points out the variety of specific groups and needs, and the need to design 'an adequate plurality' of policy means in order to respect the specific capability determinants of the specific groups (Dreze and Sen, 1989, p. 102).

\section{The capability approach - 3: Adaptive preferences and reasoned reflection}

'Adaptive preference' is one of the most discussed topics in the capability approach community and has important implications for projects that aim for social change. It is often cited as a reason for not adopting preference fulfilment or felt satisfaction as lead criterion. For 'deprived groups may be habituated to inequality, may be unaware of possibilities of social change, may be hopeless about upliftment of objective circumstances of misery, may be resigned to fate, and may be willing to accept the legitimacy of the established order.' Sen (1990, p. 127). Social moulding per se is not the problem: most human preferences are socially moulded; education too involves some social moulding; and public reasoning is an attempt to remould our own and other people's preferences. Instead the objection arises when preferences are socially moulded in questionable ways; in particular, when people become inured to their own exploitation. Even if preferences could not be remoulded, some preferences are objectionable, e.g. preferences which ignore impacts on other people, preferences even for harming some other people, and preferences for harming oneself.

Biggeri and Ferrannini discuss countering adaptive preferences or, more accurately put, ensuring that preferences are formed under acceptable conditions. Various innovative tools can promote informed reflective reasoning; including, when discussing community priorities, role-playing to build empathy and perhaps encourage adoption of a 'quasi-impartial spectator' role.

Walker examines women's adaptive preferences in an economic project in Georgia, using his enriched time survey analysis. This highlights that while time is one constraint to women's capabilities, there are other contextual constraints, including factors that affect women's scope to be economically active, and hegemonic social attitudes about gender roles. Some responses from the gender survey reveal attitudes that women's chief focus should be on domestic work and caring for the family (which appears prioritized over the expansion of economic activities that is envisaged by the project). These inequalities in division of domestic tasks are perceived as a natural order. We need to assess whether decisions about time use are made as 'free choices', exploring the trade-offs that women and men make, the priorities they have, and what motivates those.

Like some of the other papers, Walker stresses how the project planning process can be made a process of exploratory discussion and research that helps to expand the agency of participants, and to change attitudes about the gendered nature of time uses and control over time, through creating spaces for critical reflection and exposure to alternative practices and norms. Unfortunately project planning can also be used in reverse fashion, to shrink agency, as Muniz Castillo's paper will show. 


\section{Tensions and necessary partners: combining multiple approaches and methods}

The capability approach contains many elements and some inevitable tensions between them. When applied to practice it also inevitably has many gaps. To deal with its own aporias - its internal tensions and dilemmas - and to become practical, the approach must link with sister approaches, both at the level of what Ferrero and Zepeda call broad 'methodological approaches' and at the more concrete levels of 'methods'/techniques and 'instruments'/administrative arrangements.

Tensions can exist between the call for use of a broad variety of sources of information versus the call for normative priority to (and sometimes even a sole focus on) capability; 'have reason to value' can be variously interpreted, with different weights given to reason; and the widely used notions of basic capabilities and required threshold levels (as in human rights conventions and the MDGs) attempt to partly limit or structure another element, the political determination of priorities via democratic debate. 'The tensions are not necessarily failings but reflect the realities of policy practice and attempts to construct a balanced system.' (Gasper, 2007, p. 346).

One internal tension concerns the weight given to 'have reason to' in the phrase 'have reason to value'. In some popular formulations 'have reason to' disappears altogether, so that 'reason to value' becomes equated to 'want' (Robeyns, 2005), leaving the capability approach similar to a market survey. Yet some people give strong favourable valuation to subordination of women, or exclusion of homosexuals, for example. Biggeri and Ferrannini's case study localities showed severe neglect of and discrimination against people with mental health problems. In contrast, and matching the 20th anniversary Human Development Report of 2010, Biggeri and Ferrannini propose methods that build-in a recognition of human rights. Their case study concerns disability rehabilitation, a program identified on human rights grounds and not because a local community prioritised it, although they recognise that since the approach is communitybased rehabilitation it must achieve community acceptance. The case shows pre-selection in saying that people with a disability have equal rights, while leaving open to local discussion how to interpret and prioritise amongst many different such rights.

A sister tension concerns paternalism. While none of the articles in this set centre on children, Biggeri and others have adapted the capability approach to children, the group where most of human development happens and where also some paternalism is essential (Biggeri, Ballet and Comim, 2011). At the same time, innovations in participatory methods offer scope for extending ideals of group reasoning on valuations, beyond the village square. James Fishkin's method of deliberative polling, for example, takes a representative sample of the relevant population and engages them in some days of becoming broadly informed about an issue and of structured discussion, prior to collecting their re-considered views.

At the level of 'methodological approaches', the capability approach expresses an ideal of a community sitting together to decide the priorities that it will seek to assure or promote. The sister human rights approach recognises that 'communities' can exclude and marginalise. It expresses the priority of some basic entitlements that stem from global and nationally endorsed values that override community habits and that ensure all residents and workers can adequately participate in the deliberating community. Nussbaum's writings attempt an intellectual framework for informing both types of discussion: the community prioritizations and the design of constitutions that set limits on those prioritizations. The sister work on human security recognises that situations are not stable, and that we must plan not only for how to fulfil aspirations but how to deal with threats and adversities, many of which are situation-specific, group-specific, intersectional, and requiring local-level attention. 
At the levels of 'methods' and 'instruments', the participatory investigation movement led by figures like Robert Chambers offers support in many ways. It has a wealth of tools, for example now also participatory statistics (Holland, 2013). But: 'While PLA [Participatory Learning and Action] offers a solid system of principles and methods suitable to facilitate the operationalization of the [Capability Approach], it lacks the consideration of the vision and principles dimension and-especially--a methodological structure', remark Ferrero and Zepeda (p.26). PLA requires a conceptual system about values, as from human rights and human capability theory, to guide the use of its tools. Similarly, the method of Outcome Mapping can be a helpful partner for a capability approach that stresses self-motivated and hence sustainable action, and a focus on patterns of behaviour change rather than on-time delivery of pre-determined goods. However, as with participatory tools, Ferrero and Zepeda warn that, in the absence of a guiding philosophy of human development, outcome mapping can become done in a top-down and technocratic way.

Biggeri and Ferrannini's paper illustrates the marriage of capability ideas with a multiplicity of methods and instruments for project planning and evaluation, especially from the participatory research repertoire. The implied context is a 'community' project receiving external funds. They describe situation analysis done through focus-group discussions that are structured by use of two formats. The Opportunity-Gap Matrix provides a current situation picture: first, the group identifies relevant capability dimensions, which become the rows of the matrix; second, it discusses the current situation via the matrix. The columns concern, for example, various determinants of conversion factors. The format could bring in threats and human security issues too, via use of these and additional columns. Biggeri and Ferrannini recognise that some sensitive issues are not suitable for group discussion, and that basic rights (e.g., for the disabled) are not matters for majority veto. The second format is the O-Gap Walk, adapted from the Power Walk; it is to assess impartially the situation of different local residents, including through participants' adoption of roles different from their own, to help build a more reflective 'we'. It will have value as an exercise in building empathy even if it were not always an accurate method for estimation.

An important additional method for organizing such discussions, reflecting a sister 'methodological approach', is provided in Manfred Max-Neef's 'human scale development' work. Its widely used matrix for thinking about needs in a particular community helps to additionally structure the reflection on community aspirations, to reduce distortion by inherited habits and hierarchies, and to promote broad thinking not only wish-list generation (Cruz et al., 2009; Guillen Royo, 2010).

Some other approaches go further, for they rest on articulated complex theories of agency. Appreciative Inquiry, for example, represents a markedly different alternative: instead of essaying participatory analysis of problems and principles of value, it breaks from conventional problem-centred project thinking by focusing on concrete cases of success and working outwards from areas of agreement and opportunity. In contrast, Susan Pick's work (Pick and Sirkin, 2010) diagnoses internalized social forces that suppress individuals, and presents pathways for countering this, not only in communitylevel projects that support individuals but eventually in nation-wide programmes of action. The work described in the paper here by Muniz Castillo is similar in its attention to change over time-scales longer than the few years of a 'project' and in its grounding in a theory of agency and motivation. She draws on Deci and Ryan's Self-Determination Theory and ideas synthesised by David Ellerman (2006). Muniz Castillo adds regarding how project organizations can inhibit agency and motivation, or instead promote them. She explores 'how methods influence agency', to use a phrase from Ferrero and Zepeda, whose own paper describes a Nicaragua project judged to have a 'perfect' logical- 
framework matrix - but no long run impact.

\section{Attention to time, change, learning}

Conventional project planning has sought to master time: to capture processes of change within definite timetables that present detailed planned change over time. Processes of human development of course involve change over time, with functionings in one period influencing capabilities and functionings in subsequent periods, as highlighted by Biggeri and Ferrannini (2014) and Gasper (2002). But the capability approach's attention to human agency can help to bring out that project processes are not mechanically predictable, and to underline dangers in the managerialist transposition of a linear control logic from a certain type of engineering project across to attempted social engineering. As illustrated by Muniz Castillo, such an approach is marred by not only inflexibility and narrow range of vision, but by typical failure to develop people, indeed by frequent use to instead diminish people. By attention to how human motivation is socially moulded by project practices, Muniz Castillo places the often more individualistic capability analysis into a required bigger picture.

Processes of human development often need a reorientation from a control perspective, to a stance of flexibility and ongoing learning; from a focus on short-term facilitated improvements, to focus on longterm action for changing behaviour, motivation and values, and organizational and institutional reform. Only then does 'scaling-up' become plausible and sustainable. Understanding, acting and transforming require emphasis on process capacities and skills, not only the 'process freedoms' which are criteria in evaluation. Pick and Sirkin's book is one exploration of this area.

Ferrero and Zepeda offer a general model for projects to promote human development, inspired by this sort of thinking. 'The traditional results chain model (inputs $\rightarrow$ activities $\rightarrow$ outputs $\rightarrow$ outcomes $\rightarrow$ impact) may be replaced by one based on the interrelated dimensions of human development defined by Alkire: ... Process Freedoms (agency) can provide the space to develop Principles and vision, which can provide a secure basis for Opportunity Freedoms and Sustainability.' (p.30) Activities in early phases of development interventions would be: '1) Mobilizing (start-up, taking the initiative); 2) Expanding participation capabilities; 3) Deliberating principles, values and vision; 4) Catalysing autonomy, partnerships; 5) Learning (including evaluative activities), adapting, mutual accountability.' (p.31) There is no one single chain for advance, instead many possible paths. Ferrero and Zepeda envisage an approach of maximum flexibility-which assumes a high degree of trust from sponsors--with longterm results only sketched, short term results specified but changeable, and evaluation conducted not in terms of supposedly clearly separable 'project impacts' but in terms of contribution to a broader development process. Mosse's Process Monitoring approach (1998) provides some relevant methods. The model proposed is similar to various progressive NGDO models, and must be partnered by study of why those have often had limited sustained spread.

The normative lens of the human capability perspective means that it can contribute to scaling-up of individual projects in a distinctive way: by opening up the subjective potential of projects to enhance people's 'right to aspire' and produce new visions of what is possible. In contrast, while scaling-up has been widely accepted as a crucial challenge for development interventions, this is normally through attempts to engineer social change 'at scale', with emphasis on the replication of 'good practices' and their dissemination through capacity building. The capability approach, in contrast, can bring an explicit focus on discussing and challenging the values and social relations which underpin the systems of entitlement that perpetuate discrimination against some social 
groups. Thus, the application of this approach to projects can potentially open up wider contestations of social norms, and needs to consider how and how far these project level contestations can act as a catalyst for wider social change.

Not unrelated to this effect of unveiling, Ferrero and Zepeda warn that, in practice, talk about learning process often fails to get institutionalised centre-stage, unlike 'logical framework' visions of controlled change. In their Morocco case, the learning process elements were reduced to decorative addenda to the log-frame blueprint model; in their Nicaragua case, the funder eventually dumped the process approach, to revert to conventional short-term output-focused management.

Much can be learnt from the record of BRAC, the largest development NGO in the world (Smillie, 2009). BRAC learnt to drop automatic assumptions that, first, affluent outsiders already understand the nature of poverty in a particular locality and how to tackle it, even when they are co-nationals; and second, that a local 'community' exists. It built an approach of long-term learning, working especially with separate groups of the disadvantaged, not least working with relatively young mothers. By building networks of local, empowered, committed agents around particular activities such as oral rehydration therapy, it established a basis for later expansion to tackle other problems and to 'go to scale' in one activity after another once the long processes of piloting had identified promisingly effective designs. The El Salvador case described by Ferrero and Zepeda has a similar character: people are not treated as subsidiary to the projects; rather project planning is subsumed within building a social movement that changes mind-sets and skills and provides a social infrastructure for a diversity of activities, partly unforeseen.

One can ask: to what forms of action is the type of model, advocated by Ferrero and Zepeda, meant to apply - everything? To public health projects, building a new university, and research budget allocation, not only to community development projects? The BRAC experience does in fact suggest its relevance to much more than small community development actions, even if not to everything.

Seeing project design and management as part of social change requires systematic attention to the impacts, favourable or unfavourable of development projects on human autonomy, argues Muniz Castillo. And it requires, as clear from BRAC and the cases described by Ferrero and Zepeda, that a human development perspective reflects critically about the power relations within processes of deliberation and decisionmaking.

\section{Power, participation and politics}

Much of the language of discussion about development projects excludes politics and power, preferring to stick with terms like 'community'. Yet behind the rigidity in practice of conventional blueprint planning and 'logical frameworks', seen in the cases described by Ferrero and Zepeda, typically lie political issues as well as conceptual ones. Deep conflicts can become revealed through use of participatory methods. Project designs that reflect existing power structures, local, national and international, are frequently not open to change through participation and learning during the project. In contrast, in the El Salvador case the local organizations did not allow themselves to be captured by an iron cage' project framework and insisted on finding funders ready to support a locally-driven learning process that developed people and changed systems, rather than only delivered pre-set outputs from pre-set inputs, outputs that may be of lesser importance and anyway are non-sustainable in the absence of organized local commitment.

Dreze and Sen (2002) argue the importance of embedding project-level deliberations in a strategy of creating and strengthening democratic institutions, not just achieving short-term impacts within the projects. If projects are to have sustained and 
wider outcomes, spaces of participation need to become institutionalized spaces of deliberation. In this manner, instead of merely addressing project design and implementation issues, deliberations support individual and collective agency to claims for rights that could go beyond a project remit. Development projects approached from a capability perspective need to engage with the democratic institutions within which participation is taking place, and to consider how to mainstream and institutionalize prohuman development changes in policy and planning.

In this special issue, Muniz Castillo and Ferrero and Zepeda's papers highlight the importance of the relationship between projects and wider policy and planning processes. Muniz illustrates the various ways that projects can positively or negatively influence socio-structural contexts: from establishing more democratic structures of deliberation to unintentionally worsening local governance. Similarly, Ferrero and Zepeda reinforce the argument that participation in development projects needs to work through local spaces of deliberation, strengthening the permanent structures of representation rather than focusing on the application of a method or participatory activity for an isolated project appraisal or design.

A third democratic element identified by Drèze and Sen (2002), besides democratic ideals and democratic institutions, is democratic practices. The practice of democracy is about the individuals' and groups' 'power with' each other generated by a process of deliberation. Crocker (2008) argues how such "power with" can feed into the evaluation of freedoms, collective action and the construction of common values. Of vital importance is enhancement of the network among grass-roots organizations. Expansion of horizontal networks and solidarity among local organizations helps to share experiences, transfer knowledge and strengthen alliances to challenge structural causes of poverty and exclusion.

Ferrero and Zepeda illustrate the importance of democratic practices to deliberate about the underlying vision and principles of development. A capability oriented development project addresses such questions, not only details of physical and administrative design; for example through using 'human scale development' formats (Cruz et al., 2009). According to Ferrero and Zepeda, by reflecting on and building some shared notions of the outcome and process of development among different groups and organizations, development projects can work as catalysts to recognize difference while also building synergies. The discussions on visions and principles have the potential to enhance both recognition and collaboration, and 'to build a long lasting compass of principles, values and vision that can guide their actions for positive change’ (28).

\section{Conclusion}

Our overview paper has tried to explore what a human capability perspective can offer development project planners and evaluators that they would not get from standard methods. The approach offers a broader vision, with awareness of unintended effects, including ones that are central to human well-being and long-run project viability. It facilitates appropriate attention to diversity of persons and their circumstances, and to the intersection of multiple dimensions that influence their lives and opportunities. It respects and engages with complexity, agency, values and motivation. It can complement frameworks that explore the nature of poverty and exclusion (for instance, sustainable livelihoods approaches and human security analyses). It is a broad 'methodological approach' that needs to partner with sister approaches, not least from human rights work, in order to compensate for its own limits, and to recognise and use existing compatible technical methods. It needs too to study organizational realities, the instruments that are adopted to structure action, and the potential for collective action 
initiatives associated to an "insurgent planning", often shaped by discourses of rights, that are based on a diagnosis of power relations and injustices. The papers in this special issue suggest that development projects need to engage with the asymmetries of power among participants, pursue the institutionalization of spaces of deliberation, and foster practices that address the vision and principles of development.

\section{Acknowledgements}

We would like to thank all the participants of the forum 'Approaching Development Projects from a Human Development and Capability Perspective' that took place prior to the 2013 Human Development and Capability Association annual conference in Managua, Nicaragua. Their insights and discussions contributed to further develop the ideas articulated in this editorial piece.

\section{References}

Alkire, S., 2002. Valuing Freedoms: Sen's Capability Approach and Poverty Reduction, Oxford: Oxford University Press.

Barnett, J., 2011. Human Security. In J. Dryzek, R. Norgaard, D. Schlosberg (eds.), The Oxford Handbook of Climate Change and Society, New York: Oxford University Press; 267-277.

Biggeri, M., J. Ballet and F. Comim (eds.), 2011. Children and the Capability Approach, Basingstoke: Palgrave Macmillan.

Biggeri, M., and A. Ferrannini, 2014. Opportunity Gap Analysis: Procedures and methods for applying the capability approach in development initiatives. Journal of Human Development and Capabilities.

Crocker, 2008. Ethics of Global Development: Agency, Capability and Deliberative Democracy, Cambridge: Cambridge University Press.

Cruz, I., Stahel A., Max-Neef, M., 2009. Towards a systematic development approach: Building on the Human-Scale Development paradigm. Ecological Economics, 68, pp. 2021-2030.

Drèze, J. and Sen, A., 1989. Hunger and Public Action, Oxford: Oxford University Press.

Drèze, J. and Sen, A., 2002. India: Development and Participation, Oxford: Oxford University Press.

Ellerman, D., 2006. Helping People Help Themselves. Ann Arbor: University of Michigan Press.

Fernández-Baldor, A., A. Boni, P.Lillo and A. Hueso, 2014. Are Technological Projects Reducing Social Inequalities And Improving People's Wellbeing ? Journal of Human Development and Capabilities.

Ferrero, G. and Zepeda, C., 2014. Rethinking Development Management Methodology: Towards a 'Process Freedom Approach', Journal of Human Development and Capabilities.

Frediani, A.A., 2007. Amartya Sen, the World Bank, and the Redress of Urban Poverty: A Brazilian Case Study, Journal of Human Development, 8(1), pp. 133-152.

Frediani, A.A., 2010. Sen's Capability Approach as a Framework to the Practice of Development, Development in Practice, 20(2), pp. 173-187.

Gasper, D. 2002. Is Sen's Capability Approach an Adequate Basis for Considering Human Development? Review of Political Economy, 14(4), 435-461.

Gasper, D., 2007. What is the Capability Approach? Its Core, Rationale, Partners and Dangers. Journal of Socio-Economics, 36(3), pp. 335-359.

Gasper, D., 2009. From Valued Freedoms to Polities and Markets: The Capability Approach in Policy Practice. Revue Tiers Monde, 198, pp. 285-302.

Gasper, D., 2013. Human Security Analysis as a Framework for Social Accountability. Pp. 393-420 in Accountable Governance for Development - Setting an Agenda Beyond 2015, Dhaka: ANSA-SAR, http:/ / ansa-sar.org/2012/index.php?option=com_content\&view=article\&id=5853:accountablegovernance-for-development-setting-an-agenda-beyond-2015\&catid=53:updates-and-news.

Guillen-Royo, M., 2010. Realising the 'wellbeing dividend' An exploratory study using the Human Scale Development approach, Ecological Economics, 70(2), pp. 384- 393.

Holland, J., ed., 2013. Who Counts? The Power of Participatory Statistics, Rugby: Practical Action Publishing.

Kleine, D., 2013. Technologies of Choice? ICTs, Development and the Capabilities Approach, Cambridge MA: The MIT Press.

Lewis, D., 2008. Nongovernmentalism and the Reorganization of Public Action. In Dar, S. and Cooke, B. (eds) The New Development Management: Critiquing the Dual Modernization, London: Zed, pp. 41-55.

Moncrieffe, J., 2007. Introduction. Labelling, power and accountability. How and why "our " categories matter. In J. Moncrieffe and R. Eyben (eds) The power of labelling, London: Earthscan, pp. 1-17.

Moncrieffe, J. and R. Eyben (eds), 2007. The power of labelling, London: Earthscan.

Moser, C. (1993). Gender, Planning and Development: Theory, Practice and Training. London: Routledge. 
Mosse, D., 1998. Process-Oriented Approaches to Development Practice and Social Research, in Mosse, D., Farrington, J. and A. Rew (eds) Development as Process: Concepts and Methods for Working with Complexity, London: Routledge, pp. 3-30.

Mowles, C., Stacey, R. and Griffin, D., 2008. What contribution can insights from the complexity sciences make to the theory and practice of development management? Journal of International Development, 20, 804-820.

Muniz Castillo, Mirtha, 2014. Development projects from the inside out: Project logic, organisational practices and human autonomy, Journal of Human Development and Capabilities

Nussbaum, M.C., 2001. Upheavals of Thought: The Intelligence of Emotions, Cambridge: Cambridge University Press

Nussbaum, M.C., 2011. Creating Capabilities: The Human Development Approach, Cambridge, MA: The Belknap Press of Harvard University Press.

O'Brien, K., and Leichenko, R. 2007, Human Security, Vulnerability and Sustainable Adaptation. HDRO Occasional Paper 2007/9. New York: UNDP.

Oosterlaken, I., and vd Hoeven, J., eds. 2012. The Capability Approach, Technology and Design, Dordrecht: Springer.

Pick, S., and J. Sirkin. 2010. Breaking the Poverty Cycle: the buman basis for sustainable development, New York: Oxford University Press.

Robeyns, I., 2005. The Capability Approach: A Theoretical Survey, Journal of Human Development, 6, pp. 93114.

Sen, A., 1990. Gender and cooperative conflicts in Tinker, I. (ed) Persistent inequalities: women and world development pp. 123-149 New York: Oxford University Press.

Sen, A., 1992. Inequality reexamined, Oxford: Clarendon Press.

Schischka, J., Dalziel, P. and Saunders, C, 2008. Applying Sen's Capabilities Approach to Poverty Alleviation Programs, Journal of Human Development, 9, pp. 229-246.

Smillie, I., 2009. Freedom from $W$ ant, Sterling, VA: Kumarian Press.

Trani, J.F., Bakhshia, P., Bellanca, N., Biggeri, M., and F. Marchetta., 2011. Disabilities through the Capability Approach lens: Implications for public policies, ALTER, European Journal of Disability Research, 5, pp. 143-157.

Walker, J., 2014. Valuing Time: Time use survey, the Capability Approach, and gender analysis. Journal of Human Development and Capabilities

Walker, J., Frediani, A. A. and J.F. Trani, 2013. Gender, difference and urban change: implications for the promotion of well-being Environment and Urbanization, 25 (1), pp. 111-124

Walker, M., 2006. Higher education pedagogies. Berkshire and New York: Society for Research into Higher Education and Open University Press. 